\title{
The Endo-Arabinanase BcAra1 Is a Novel Host-Specific Virulence Factor of the Necrotic Fungal Phytopathogen Botrytis cinerea
}

\author{
Majse Nafisi, ${ }^{1}$ Maria Stranne, ${ }^{1}$ Lisha Zhang, ${ }^{2}$ Jan A. L. van Kan, ${ }^{2}$ and Yumiko Sakuragi ${ }^{1}$ \\ ${ }^{1}$ University of Copenhagen, Faculty of Science, Department of Plant and Environmental Sciences, Thorvaldsensvej 40, \\ 1871 Frederiksberg, Denmark; ' ${ }^{2}$ Wageningen University, Laboratory of Phytopathology, Droevendaalsesteeg 1, 6708 PB \\ Wageningen, The Netherlands
}

Submitted 10 February 2014. Accepted 1 April 2014.

\begin{abstract}
The plant cell wall is one of the first physical interfaces encountered by plant pathogens and consists of polysaccharides, of which arabinan is an important constituent. During infection, the necrotrophic plant pathogen Botrytis cinerea secretes a cocktail of plant cell-wall-degrading enzymes, including endo-arabinanase activity, which carries out the breakdown of arabinan. The roles of arabinan and endo-arabinanases during microbial infection were thus far elusive. In this study, the gene Bcaral encoding for a

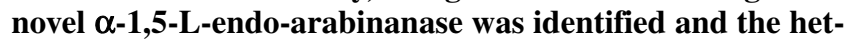
erologously expressed BcAra1 protein was shown to hydrolyze linear arabinan with high efficiency whereas little or no activity was observed against the other oligo- and polysaccharides tested. The Bcara1 knockout mutants displayed reduced arabinanase activity in vitro and severe retardation in secondary lesion formation during infection of Arabidopsis leaves. These results indicate that BcAra1 is a novel endo-arabinanase and plays an important role during the infection of Arabidopsis. Interestingly, the level of Bcara1 transcript was considerably lower during the infection of Nicotiana benthamiana compared with Arabidopsis and, consequently, the $\Delta B$ cara 1 mutants showed the wild-type level of virulence on $N$. benthamiana leaves. These results support the conclusion that the expression of Bcaral is host dependent and is a key determinant of the disease outcome.
\end{abstract}

The plant cell wall provides a recalcitrant barrier consisting of a network of cellulose and hemicellulose embedded within a matrix of pectin polysaccharides and cell wall glycoproteins (Carpita and Gibeaut 1993). Arabinan is one of the most abundant neutral-sugar side chains of a class of pectins (namely, rhamnogalacturonan I) and is found in the primary cell wall of all plants. It consists of $\alpha-1,5$-linked arabinosyl residues with

M. Nafisi, M. Stranne, and L. Zhang contributed equally to the work.

Current address for L. Zhang: Department of Biology, University of Kaiserslautern, Erwin-Schrödinger-Straße 22, D-67663 Kaiserslautern, Germany.

Corresponding author: Y. Sakuragi; E-mail: ysa@life.ku.dk

* The $e$-Xtra logo stands for "electronic extra" and indicates that five supplementary figures and one supplementary table are published online and that Figures 1, 5, and 9 appear in color online.

(C) 2014 The American Phytopathological Society the chain length varying from 1 to 50 residues, which can be branched at the $O-2$ and $O-3$ with single or short-chain $\alpha$ arabinosyl residues (Mohnen 2008; Ridley et al. 2001). The bulk of arabinan is highly mobile in hydrated cell walls (Ha et al. 2005), while a fraction of arabinan can tightly associate with cellulose microfibrils (Vignon et al. 2004; Zykwinska et al. 2005) and participate in polymer cross linkage via ferulic acid esters (Levigne et al. 2004; Ralet et al. 2005) and cross linkage between pectin and xyloglucan (Thompson and Fry 2000). These features of arabinan likely contribute to the cellwall elasticity and mechanical properties, as has been proposed in Arabidopsis stems (Verhertbruggen et al. 2013) and guard cells (Jones et al. 2003) and in desiccant-tolerant plants during water-deficit stress (Moore et al. 2006, 2008). Furthermore, arabinan has been suggested to serve as a storage reserve during seedling establishment (Gomez et al. 2009). Thus, arabinan likely plays a wide range of roles in plants, although its roles during pathogen infection is unknown.

Degradation of plant cell walls is a common feature of necrotrophic phytopathogens and contributes to pathogenesis by aiding tissue invasion and pathogen dissemination (Williamson et al. 2007). During infection, cell-wall-degrading enzyme activities such as cellulases, xylanases, endo-glucanases, endopolygalacturonases (endo-PG), and arabinanases have been detected in apple and tomato fruit infected with the necrotrophic fungal pathogen Botrytis cinerea (Urbanek and Zalewskasobczak 1984; Verhoeff and Warren 1972). A number of studies on the secretome of $B$. cinerea in different culture conditions have revealed that many cell-wall-degrading enzymes were secreted when the fungus was grown in media with plant tissues as the only carbon source, although the abundance and identity of secreted enzymes varied between the experiments and the plant extracts used (Espino et al. 2010; FernandezAcero et al. 2010; Shah et al. 2009a,b). The large capacity for plant cell-wall degradation was further illustrated by the identification in the $B$. cinerea genome of 367 genes encoding putative CAZymes, including 118 genes unambiguously associated with plant cell-wall degradation (Amselem et al. 2011).

The host range of $B$. cinerea is restricted to plants with high pectin content in the cell wall (ten Have et al. 2002), and many studies have focused on the role of enzymes that de-esterify and depolymerize the pectic backbones, including endo-PG, exo-PG, pectin methylesterases, and pectin/pectate lyases, in infection by $B$. cinerea (Zhang and van Kan 2013b). When purified endo-PG were infiltrated into leaf tissues, rapid loss of cell wall integrity followed by tissue collapse and cell death were observed (Kars et al. 2005a), which shows that these en- 
zymes are involved in tissue maceration. The $B$. cinerea genome contains six endo-PG-encoding genes, and targeted knockout mutants $\Delta B c p g 1$ and $\Delta B c p g 2$ had reduced virulence on a number of plant species (Kars et al. 2005a; ten Have et al. 1998; Zhang and van Kan 2013a), whereas the knockout mutants $\Delta B$ cpg3 to -6 had no detectable impact on virulence (Kars 2007). Deletion of the pectin-methylesterase-encoding gene, Bcpme 1 , in strain Bd90 produced mutants with reduced ability to colonize apple, grape, and Arabidopsis leaves (ValetteCollet et al. 2003), whereas deletion of Bcpme 1 and Bcpme 2 in strain B05.10 had no effect on virulence when tested on tomato and grapevine leaves (Kars et al. 2005b).

In contrast, roles of arabinan-degrading enzymes in virulence of phytopathogenic fungi have remained elusive to date. Circumstantial evidence suggests that arabinan-degrading enzymes are involved during pathogenesis. It has been reported that arabinanases are produced during infection of plants by Fusarium oxysporum (Cooper and Wood 1975; Houterman et al. 2007), F. roseum "Avenaceum" (Mullen and Bateman 1975), Verticillium albo-atrum (Cooper and Wood 1975), Cochliobolus carbonum (Ransom and Walton 1997), and B. cinerea (Urbanek and Zalewskasobczak 1984). An uncharacterized arabinanase, most likely exo-acting, was identified in the xylem sap of tomato plants infected by $F$. oxysporum (Houterman et al. 2007), along with a number of effector proteins. Further-
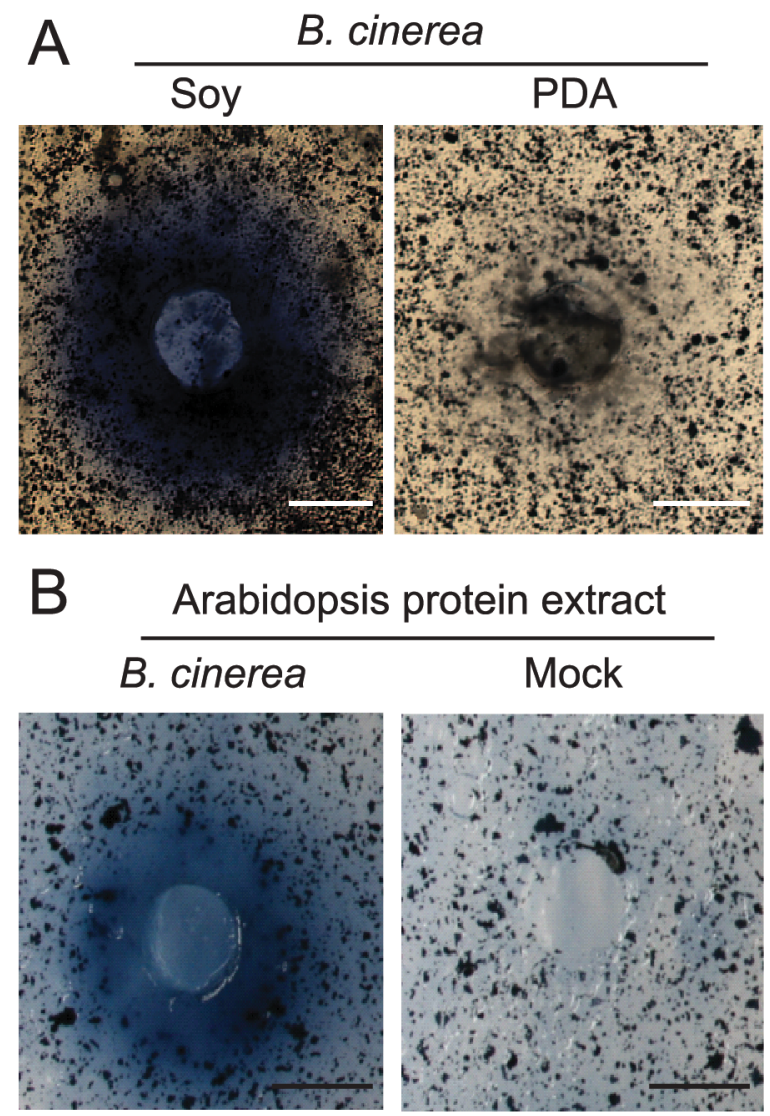

Fig. 1. Arabinan-degrading activity of Botrytis cinerea wild-type strain (IK2018) visualized by agar plate diffusion assay with azurine-dyed and cross-linked (AZCL)-arabinan. A, B. cinerea grown on soy peptone medium (Soy) or potato dextrose agar (PDA) overlaid with AZCLarabinan. B. cinerea spore suspension $\left(10^{5}\right.$ spores $\left.\mathrm{ml}^{-1}\right)$ was spotted in each well. Plates were incubated for $72 \mathrm{~h}$ before being photographed. Scale bars $=0.5 \mathrm{~cm}$. B, Arabinan-degrading activity in Arabidopsis leaves infected with $B$. cinerea. Crude protein extracts from Arabidopsis leaves at $72 \mathrm{~h}$ postinfection with $B$. cinerea or buffer (mock) were spotted on AZCL-arabinan plates. Each well contains $20 \mu \mathrm{l}$ of protein extract. Plates were incubated for $24 \mathrm{~h}$. Scale bars $=0.5 \mathrm{~cm}$. more, a correlation was observed between $\alpha$-arabinofuranosidase activity in vitro and the virulence of 119 Sclerotinia fructigena strains mutagenized with $N$-methyl- $N^{\prime}$-nitrosoguanidine on apple fruit, whereas no correlation was found between virulence and activity of pectin methylesterases or PG (Howell 1975). Arabinofuranosidase-deficient mutants of $S$. trifoliorum were isolated after mutagenesis with $N$-methyl- $N^{\prime}$-nitrosoguanidine and exhibited reduced growth on winter pea stems compared with the parental strain (Rehnstrom et al. 1994). However, the exact nature of the mutations in these strains has not yet been identified.

The aim of the present study was to expand our knowledge regarding the role of endo-arabinanase in virulence of $B$. cinerea. Arabinan is ubiquitous and abundant in primary cell walls of all higher plants. $B$. cinerea was chosen because it is a major cause of postharvest loss of fruit, vegetables, and cut flowers and is reported to infect more than 200 plant species (Dean et al. 2012). The broad host range has been attributed to an arsenal of secreted cell-wall-degrading enzymes, which degrade tissue from a variety of plant species (van Kan 2006). Therefore, greater understanding of infection strategies employed by this fungus is of considerable importance in agriculture. In this study, we isolated the Bcaral gene from B. cinerea, demonstrated endo-acting arabinanase activity of BcAra1, and revealed the importance of this enzyme during infection of plant tissue.

\section{RESULTS}

\section{B. cinerea produces arabinan-degrading activities in vitro and in planta.}

Production of arabinan-degrading enzymes by $B$. cinerea IK2018 was tested in vitro and during infection of Arabidopsis leaves. Strain IK2018 was originally isolated from grape and is virulent on Arabidopsis (Manabe et al. 2011). When grown on a soy peptone medium containing azurine-dyed and crosslinked (AZCL) arabinan, B. cinerea IK2018 caused the formation of blue haloes around the inoculation sites, indicative of arabinan-degrading activity (Fig. 1A). A similar result was obtained when Gamborg's B5 medium was used instead of the soy peptone medium (data not shown). In contrast, no halo was observed when the fungus was grown on potato dextrose agar (PDA) medium (Fig. 1A). When crude protein extracts from Arabidopsis leaves infected with $B$. cinerea for $72 \mathrm{~h}$ were incubated on a solidified sodium citrate buffer containing AZCL-arabinan, blue halos also developed around the wells, whereas no color development was observed for crude protein extracts from mock-treated leaves (Fig. 1B). Taken together, these results indicate that $B$. cinerea IK2018 produces arabinandegrading activities when grown in the soy peptone and Gamborg's B5 media and during infection of Arabidopsis but not when grown in PDA medium.

\section{BC1G_10322/BcAra1 is identified as a candidate endo-arabinanase.}

It was suspected that an endo-arabinanase is at least partially responsible for the arabinan-degrading activities produced by $B$. cinerea because AZCL-arabinan is a highly sensitive substrate for endo-arabinanase activity (McCleary et al. 1988). In order to search for an endo-arabinanase in B. cinerea, the amino acid sequence of the functionally characterized endoarabinanase Aral from Aspergillus aculeatus (Skjot et al. 2001) was used as the query in BLAST search against the genome sequence of $B$. cinerea B05.10 (version 1). One homologous sequence was found to be encoded by the locus ID $\mathrm{BC} 1 \mathrm{G}_{-}$10322. It encodes a protein of 319 residues showing $63 \%$ identity to the query sequence (Supplementary Fig. S1) 
and is annotated as a hypothetical protein similar to $\alpha-1,5-\mathrm{L}$ endo-arabinanase. The $\mathrm{BC} 1 \mathrm{G} \_10322$ gene product is assigned to the CAZY GH43 family. Reciprocal BLAST search using BC1G_10322 as the query against the nonredundant protein database identified a number of microbial sequences belonging to the GH43 family, and all of them are annotated as putative endo-arabinanases (Table 1). Another GH43 family member was identified in the $B$. cinerea B05.10 version 1 genome as having significant sequence similarities to Aral but it is more likely to be an arabinofuranosidase because it has a sequence similarity higher than that in $A$. niger (Table 2). In addition to the GH43 family proteins, the genome of $B$. cinerea B05.10 encodes four additional putative arabinofuranosidases assigned to CAZY families GH51, GH54, and GH62 (Table 2). The amino acid alignment of BC1G_10322 with BsArb43A and CjArb43A, functionally and structurally characterized endoarabinanase and exo-arabinanase from Bacillus subtilis and Cellovibrio japonicum, respectively, revealed the presence of conserved catalytic carboxylate amino acids aspartate 14, aspartate 133, and glutamate 185 (position based on the mature form of BsArb43A) across the fungal orthologs. In addition, tryptophan 74 and phenylalanine 151 , located at the -1 position of the substrate-binding site, are also conserved among fungal arabinanases and their orthologs (Nurizzo et al. 2002). Taken together, these results suggested that BC1G_10322 encodes an endo-arabinanase and, therefore, we designated it as BcAra1. The N-terminal sequence of BcAral was predicted by SignalP (Petersen et al. 2011) to contain a canonical signal peptidase cleavage site between the 18th and 19th residues, which suggests that BcAral is a secreted enzyme.

\section{Isolated BcAra1 has endo-arabinanase activity.}

The coding sequence of Bcaral was amplified from total RNA extracted from B. cinerea-infected Arabidopsis leaves. Attempts to express BcAral that was devoid of the predicted signal peptide and was N-terminally fused to a His-tag failed to produce detectable accumulation of the protein and arabinandegrading activity in Escherichia coli and Nicotiana benthamiana. The full-length BcAral without a tag and a chimera wherein the predicted native signal peptide was replaced by a signal peptide from the $\alpha$ mating factor (Emr et al. 1983) from Pichia pastoris and N-terminally fused to a His-tag in P. pastoris also failed to produce detectable expression of the pro- teins and the activities. Only when the full-length BcAral was expressed in $N$. benthamiana was an arabinan-degrading activity detectable. Two versions of BcAral were expressed: a native version and a version with a His-Asp-Glu-Leu (HDEL) tag fused to the $\mathrm{C}$ terminus for retention in the endoplasmic reticulum for high-level protein expression. Both versions were cloned in the MP27 vector derived from pCambia3300 and

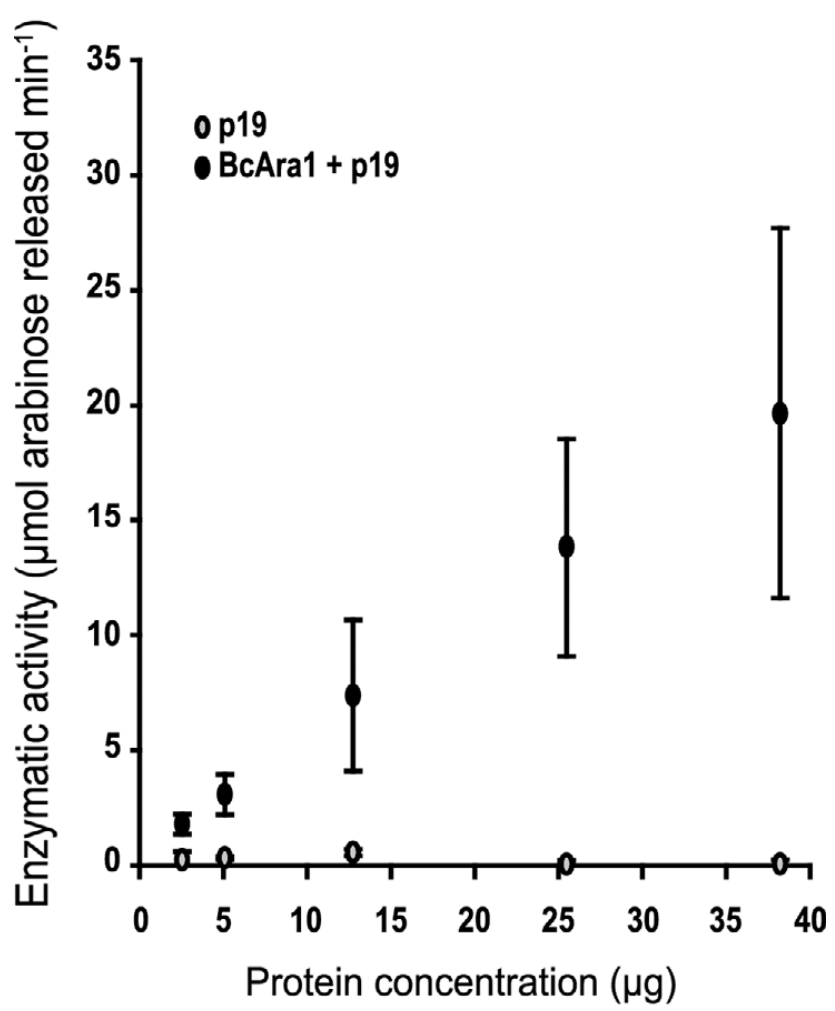

Fig. 2. Catalytic activity assay of recombinant BcAra1. Degradation of linear arabinan by protein extracts from Nicotiana benthamiana transiently expressing the control (p19) or expressing BcAra1 and p19 (BcAra1+p19). Activity was assayed by incubating linear arabinan $(0.5 \%, \mathrm{wt} / \mathrm{vol})$ and increasing amounts of the $N$. benthamiana extracts at $37^{\circ} \mathrm{C}, \mathrm{pH} 5.5$, for $1 \mathrm{~h}$ followed by 3,5 dinitrosalicylic acid reducing sugar assay. Values are means of three biological replicates \pm standard deviation.

Table 1. Top 10 Blast hits when using BC1_10322P as the query

\begin{tabular}{|c|c|c|c|}
\hline Accession & Description & Identity (\%) & Similarity $(\%)$ \\
\hline gi|156039571 & Hypothetical protein SS1G_11922, Sclerotinia sclerotiorum 1980 & 88 & 94 \\
\hline gi 145241582 & Arabinan endo-1,5- $\alpha$-L-arabinosidase C, Aspergillus niger CBS 513.88 & 64 & 76 \\
\hline gi| 358373624 & Arabinan endo-1,5- $\alpha$-L-arabinosidase A, A. kawachii IFO 4308 & 65 & 76 \\
\hline gi|320589382 & Glycoside hydrolase family 43, Grosmannia clavigera kw 1407 & 64 & 80 \\
\hline gi| 328852134 & Glycoside hydrolase family 43, Melampsora larici-populina 98AG31 & 64 & 73 \\
\hline gi|74638570 & Endo- $\alpha-1,5$-arabinanase precursor, $A$. aculeatus CBS 101.43 & 63 & 77 \\
\hline gi| 348673668 & Hypothetical protein PHYSODRAFT_335251, Phytophthora sojae & 61 & 74 \\
\hline gi_70998885 & Extracellular putative endo-1,5- $\alpha$-L-arabinase, A. fumigatus Af293 & 61 & 76 \\
\hline gi| 119490178 & Extracellular putative endo-1,5- $\alpha$-L-arabinase, Neosartorya fischeri NRRL 181 & 62 & 76 \\
\hline gi 255946555 & Pc20g15730, Penicillium chrysogenum Wisconsin 54-1255 & 59 & 73 \\
\hline
\end{tabular}

Table 2. Putative arabinan-degrading enzymes encoded in the genome of Botrytis cinerea B05.10

\begin{tabular}{lll}
\hline Glycosyl hydrolase family & Locus tag & \\
\hline GH43 & BC1G_10322 & Arabinan endo-1,5- $\alpha$-L-arabinosidase C in Aspergillus niger CBS (64\% identity, 76\% similarity) \\
GH51 & BC1G_12138 & $\alpha$-L-arabinofuranosidase in Aspergillus niger (57\% identity, 71\% similarity) \\
& BC1G_08372 & $\alpha$-L-arabinofuranosidase in Neosartorya fischeri NRRL181 (57\% identity, 67\% similarity) \\
GH54 & BC1G_10025 & $\alpha$-L-arabinofuranosidase in A. fumigatus Af293 (65\% identity, 76\% similarity) \\
GH62 & BC1G_04994 & $\alpha$-L-arabinofuranosidase in Penicillium purpurogenum (83\% identity, 89\% similarity) \\
\hline
\end{tabular}

${ }^{a}$ Defined by the CAZy database. BLAST analysis with BLOSUM62 and the cut off of E value $<10^{-3}$ was used. 
expressed under control of the Cauliflower mosaic virus $35 \mathrm{~S}$ promoter. Furthermore, a suppressor of post-transcriptional silencing protein P19 was co-expressed with BcAral and BcAra1-HDEL or the empty MP27 vector (negative control) in order to further ensure a high-level protein expression (Voinnet et al. 2003). Crude protein extracts from $N$. benthamiana expressing BcAra1, BcAra1-HDEL, or the empty vector control were desalted and linear arabinan from sugar beet was used as substrate to assay for enzyme activity (Fig. 2). Both crude extracts containing the native and the HDEL-tagged BcAral showed a similar level of enzyme activity per total extracted protein, indicating that the presence of the HDEL tag did not considerably alter the expression of BcAra1 (data not shown). The protein extract derived from $N$. benthamiana transformed with the empty vector did not have any detectable activity above the baseline, indicating that there is no endogenous endo-arabinanase activity in $N$. benthamiana leaves under the conditions tested (Fig. 2).

Various plant cell wall polysaccharides were tested as substrates. Linear arabinan and de-branched arabinan derived

Table 3. Activity of Nicotiana benthamiana extracts expressing recombinant BcAra1 on arabinose-containing substrates

\begin{tabular}{lc}
\hline Substrate & Enzymatic activity $\left(\mathbf{U ~ m g}^{\mathbf{- 1}}\right)^{\mathbf{a}}$ \\
\hline Linear arabinan & $11.4 \pm 1.4$ \\
Debranched arabinan & $15.7 \pm 2.7$ \\
Sugar beet arabinan & $1 \pm 1.7$ \\
Larch wood arabinogalactan & $\mathrm{ND}$ \\
Wheat arabinoxylan & $\mathrm{ND}$ \\
Birch xylan & $\mathrm{ND}$ \\
Barley $\beta$-glucan & $\mathrm{ND}$ \\
Arabinobiose & $\mathrm{ND}$ \\
\hline
\end{tabular}

${ }^{\mathrm{a}} \mathrm{ND}=$ no detectable activity $\left(<0.1 \mathrm{U} \mathrm{mg}^{-1}\right)$

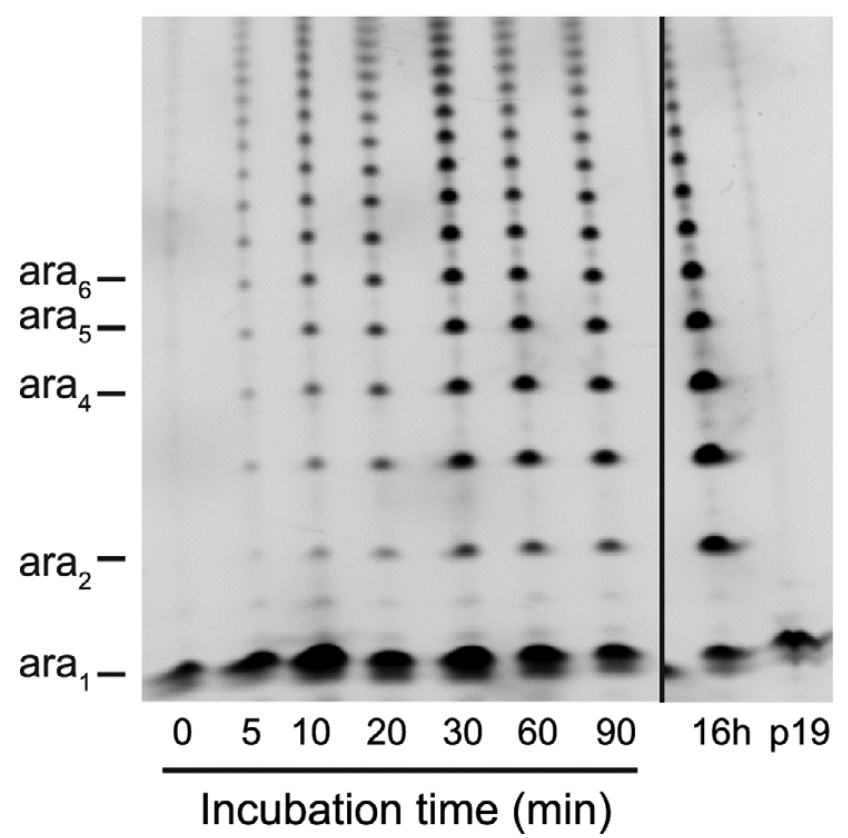

Fig. 3. Polysaccharide analysis using carbohydrate gel electrophoresis of hydrolysis products obtained from linear arabinan incubated with recombinant BcAra1. Linear arabinan from sugar beet was incubated with protein extracts from Nicotiana benthamiana expressing BcAra1 and p19 for the indicated times. Standards: $\operatorname{ara}_{1}=$ arabinose; $\operatorname{ara}_{2}=$ arabinobiose; $\operatorname{ara}_{4}=$ arabinotetraose; $\operatorname{ara}_{5}=$ arabinopentaose; $\operatorname{ara}_{6=}$ arabinohexaose; $16 \mathrm{~h}=$ protein extracts from $N$. benthamiana expressing BcAra1+p19 incubated with linear arabinan for $16 \mathrm{~h}$; and p19 = protein extracts from $N$. benthamiana expressing p19 alone incubated with linear arabinan for $16 \mathrm{~h}$. from sugar beet were depolymerized by the crude BcAra1 extracts whereas branched arabinan, arabinoxylan, arabinogalactan, xylan, and galactan were not (Table 3 ). This indicates that the expressed enzyme is specific to the $\alpha-1,5$-arabinan linkage. In order to further assess the mode of action, the crude BcAra1 extract was incubated with 1,5- $\alpha$-arabinobiose. The extract failed to cleave arabinobiose, which suggests that BcAra1 is an endo-acting arabinanase (Table 3). Linear arabinan was incubated with crude BcAral extract at various time intervals and the hydrolysis products were studied by polysaccharide analysis using carbohydrate gel electrophoresis (PACE). The background level of arabinose stems from the plant extract, in which a proportion of the arabinose remained after desalting and excessive washing with buffer. The results showed that hydrolysis products ranged in size from arabinobiose to much larger arabinooligomers at a similar quantity after $20 \mathrm{~min}$ (Fig. $3)$. As the reaction proceeded, the size distribution of arabinooligosaccharides shifted from longer to shorter and, after $16 \mathrm{~h}$ of incubation, the most abundant arabinooligosaccharides were arabinoheptaose and shorter based on visual (Fig. 3) and quantitative assessment by Image $\mathbf{J}$ (data not shown). Taken together, these results demonstrate that BcAra1 is an endo-arabinanase.

\section{Knockout mutants of Bcara1 are deficient in endo-arabinanase activity.}

To study the biological role of Bcara1 in virulence of $B$. $c i$ nerea, knockout mutants were constructed. A large part of the coding sequence of Bcaral was exchanged by a cassette containing the $h p h$ gene, which confers resistance to hygromycin (Fig. 4A). B. cinerea transformants resistant to hygromycin were screened for homologous gene replacement by polymerase chain reaction (PCR) (Fig. 4B) and three independent transformants ( $\Delta$ Bcara1-IK10, $\Delta$ Bcara1-IK12, and $\Delta$ Bcara $1-\mathrm{IK} 18)$ were identified as homozygous Bcara1::hph mutants. In con-

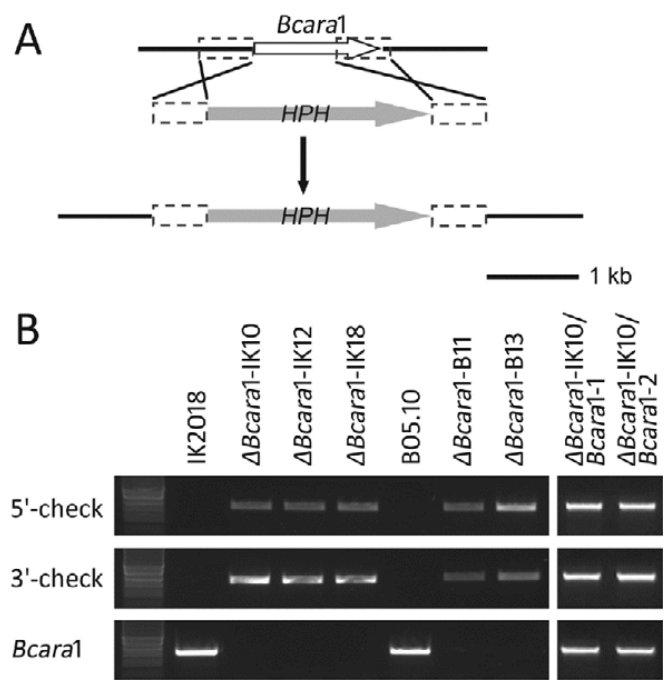

Fig. 4. Botrytis cinerea mutant construction. A, Organization of Bcara1 locus before and after homologous recombination in the wild type. Orientation of the target gene and $h p h$ are indicated by white and gray arrows, respectively. Upstream and downstream flanks of target genes are shown with gray dashed-line frames. B, Polymerase chain reaction analysis of wild-type strain (IK2018 and B05.10) and knockout mutant strains. Mutants $\Delta$ Bcara 1 -IK10, $\Delta$ Bcara 1 -IK12, and $\Delta$ Bcara 1 -IK18 were generated in IK2018 recipient; mutants $\Delta B$ cara 1 -B11 and $\Delta$ Bcara1-B13 were generated in B05.10 recipient. Complemented strains $\Delta$ Bcara1-IK10/Bcara1-1 and $\Delta$ Bcara1-IK10/Bcara $1-2$ were generated using the $\Delta$ Bcara 1 -IK10 mutant as recipient. The genomic DNA of each strain was used to verify homologous recombination by using primer pairs $5.1 / 23$ and $3.1 / 22$ for checking the $5^{\prime}$ and $3^{\prime}$ recombination, respectively. The absence of the target gene in the knockout mutants was verified using primers 5.1 and 3.1. 
trast to IK2018, the three transformants failed to degrade AZCL-arabinan after $24 \mathrm{~h}$ of growth (Fig. 5), and this activity was restored in $\Delta$ Bcara1-IK10 complemented with the wildtype gene (Supplementary Fig. S2). Two independent knockout mutants in B. cinerea B05.10 were also generated and similar results were obtained (data not shown). The results indicate that BcAral is responsible for the primary arabinandegrading activity in $B$. cinerea strains IK2018 and B05.10 under the conditions tested.

Arabinan-degrading activities in the culture supernatants of the wild type (IK2018) and $\Delta B$ cara1-IK10 mutant were characterized by PACE. The wild type and the $\triangle B$ cara1-IK10 mutant were grown in Gamborg's B5 medium containing $0.5 \%$ (wt/vol) arabinose as the sole carbon source and, after 4 days, the culture media were separated from the fungal biomass by centrifugation. For desalting and removal of arabinose, the supernatants were passed through a size-exclusion filter that retained molecules larger than $10 \mathrm{kDa}$. The obtained fractions were subsequently incubated with linear arabinan. The culture supernatants from the wild type gave rise to products with sizes that ranged from arabinobiose to arabinooligosaccharides larger than a degree of polymerization (DP) of 6 (Fig. 6). Moreover, the pattern of products generated by the wild-type sample was virtually identical to that generated by a commercial endo-arabinanase from A. niger. In contrast, a commercial arabinofuranosidase from $A$. niger mainly generated arabinose and a low level of arabinobiose. The culture supernatants obtained from $\Delta$ Bcara 1 -IK10 failed to generate arabinooligosaccharides with DP of 3 or larger over the course of time analyzed (Fig. 6).

The impact of loss of Bcara1 on growth was assessed on several types of media. On PDA, the mutants showed no significant difference in radial growth compared with the wild

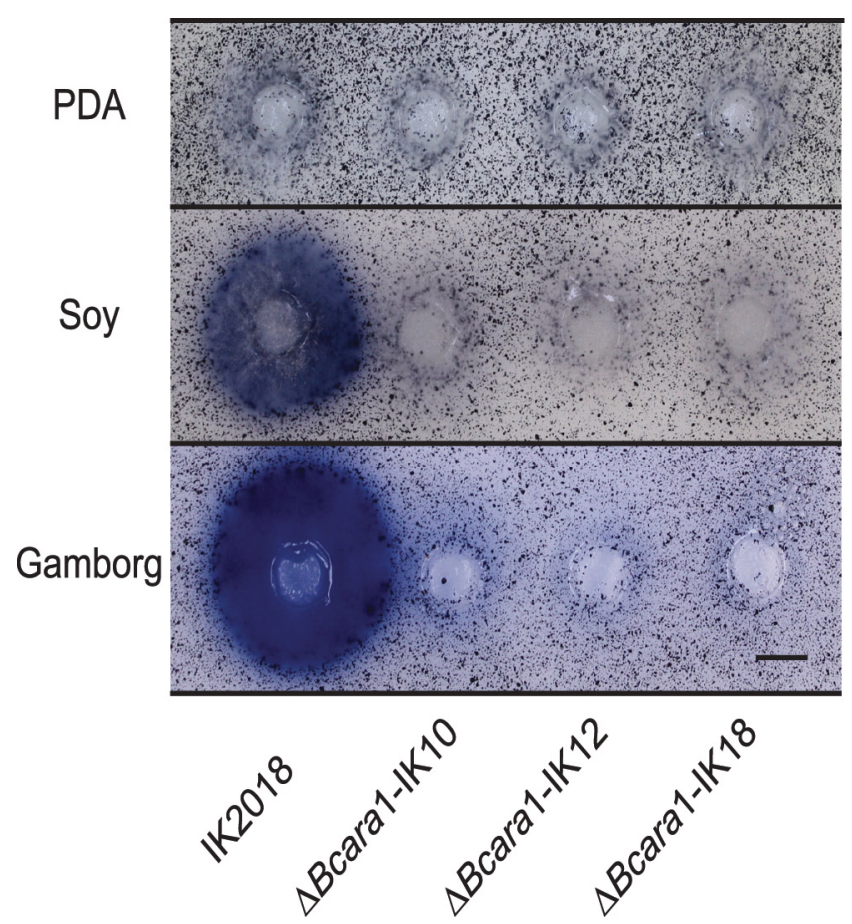

Fig. 5. Arabinan-degrading activity of Botrytis cinerea wild type (IK2018) and three independent $\triangle B$ cara 1 mutants in various media. Arabinan depolymerization by $B$. cinerea IK 2018 and $\Delta$ Bcara 1 mutants on potato dextrose agar (PDA), soy peptone medium (Soy), and Gamborg's B5 medium (Gamborg) overlaid with azurine-dyed and cross-linked (AZCL)arabinan. B. cinerea spore suspension $\left(20 \mu \mathrm{l}\right.$ of $5 \times 10^{5}$ spores $\left.\mathrm{ml}^{-1}\right)$ was spotted in each well and the plates were incubated at $25^{\circ} \mathrm{C}$ for $24 \mathrm{~h}$. Scale bars $=0.5 \mathrm{~cm}$. type (Fig. 7A). When grown on arabinan as the sole carbon source in Gamborg's B5 medium, the mutants had severely retarded growth by $24 \mathrm{~h}$; thereafter, the growth rate increased to the level comparable with that of the wild type (Fig. 7B). These results show that, within the first $24 \mathrm{~h}$ after inoculation, Bcara 1 is essential for efficient utilization of linear arabinan in the growth media, and that Bcaral thus provides the major endo-arabinanase activity under the conditions tested.

\section{Bcara1 is expressed and plays a role} as a virulence factor during infection of Arabidopsis.

Expression of the Bcaral gene in planta was measured by quantitative real-time PCR in Arabidopsis leaves infected with B. cinerea. Detached leaves were spot-inoculated with $B$. $c i$ nerea spores and sampled at various time points for RNA extraction. No expression of Bcara1 was detectable at 16 and 32 $\mathrm{h}$ postinoculation (hpi) whereas a highly variable expression was observed at $48 \mathrm{hpi}$ and a consistent and significant expression at 72 hpi (Fig. 8A). The fungal biomass was assessed by monitoring the expression of the BcactA gene that encodes actin (Benito et al. 1996). The transcript of BcactA was noticeable at $16 \mathrm{hpi}$ and increased exponentially in the subsequent time points (Fig. 8B). Therefore, it is likely that that expression of Bcaral is not a major contributing factor during the initial colonization of Arabidopsis.

The effect of deletion of the Bcaral gene on virulence of $B$. cinerea was tested on Arabidopsis. Detached leaves of Arabidopsis were spot inoculated with a $B$. cinerea spore suspension, and lesion development followed over time. Spore germination and primary necrotic lesion development were similar for the wild type and mutants but the lesion expansion was reduced in the mutants, as shown by the smaller lesion sizes at 3 days postinfection (dpi) (Fig. 8C and E). In addition, B. ci-

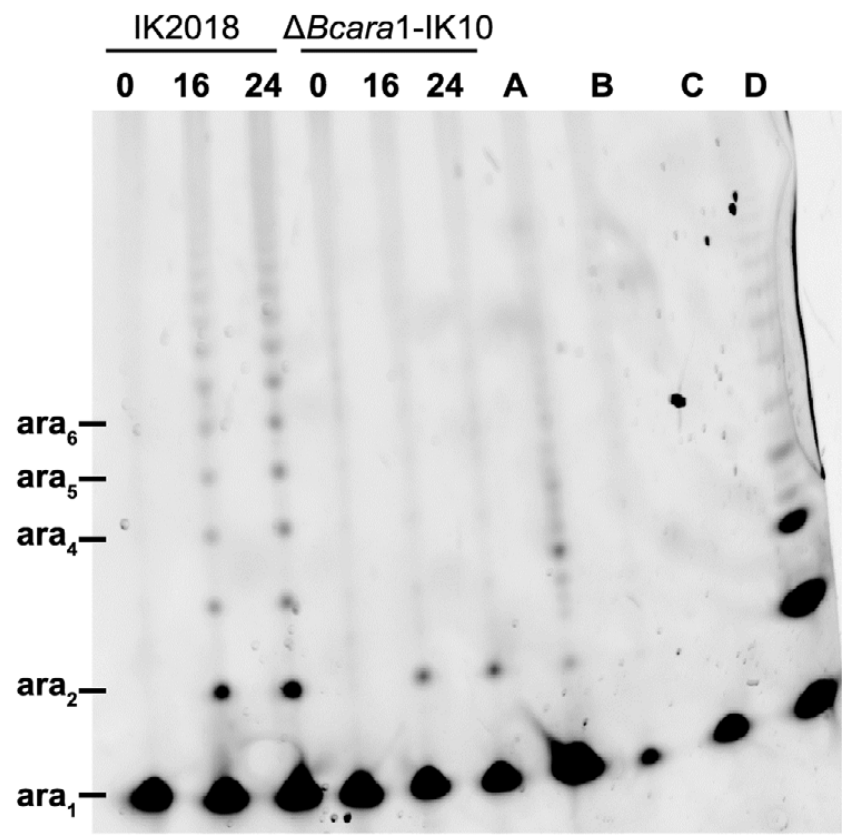

Fig. 6. Hydrolysis products of linear arabinan by culture supernatants of Botrytis cinerea wild type (IK2018) and $\Delta$ Bcara1-IK10. desalted supernatants of liquid cultures were incubated with linear arabinan $(0.5 \%$ $\mathrm{wt} / \mathrm{vol}$ ) for 0,16 , and $24 \mathrm{~h}$ and the hydrolysis products were analyzed by polysaccharide analysis using carbohydrate gel electrophoresis. Samples with B. cinerea culture supernatant (column B) or linear arabinan (column C) alone, as well as samples with commercial Aspergillus niger arabinofuranosidase (column A) and endo-arabinanase (column D) were incubated for $24 \mathrm{~h}$. Standards: $\operatorname{ara}_{1}=\operatorname{arabinose} ; \operatorname{ara}_{2}=$ arabinobiose; $\operatorname{ara}_{5}=$ arabinopentaose; and ara $_{6}=$ arabinohexaose. 
nerea biomass, as quantified by immunodetection, was greatly reduced on leaves inoculated with the mutants (Fig. 8D). Taken together, these results show that Bcaral is important for full virulence on Arabidopsis.

Based on the reduced virulence of the $\Delta B$ cara 1 mutants on Arabidopsis, it was hypothesized that arabinan serves as a carbon source for $B$. cinerea during infection. $B$. cinerea IK2018 and the $\Delta$ Bcara1-IK10 mutant were grown on Gamborg's B5 media containing cell wall polysaccharides isolated from Arabidopsis leaves as the sole carbon source. IK2018 and the $\Delta$ Bcara1-IK10 mutant displayed a similar colony size (Supplementary Fig. S3). Thus, arabinan may not serve as a main source of carbon by $B$. cinerea when grown on plant tissues.
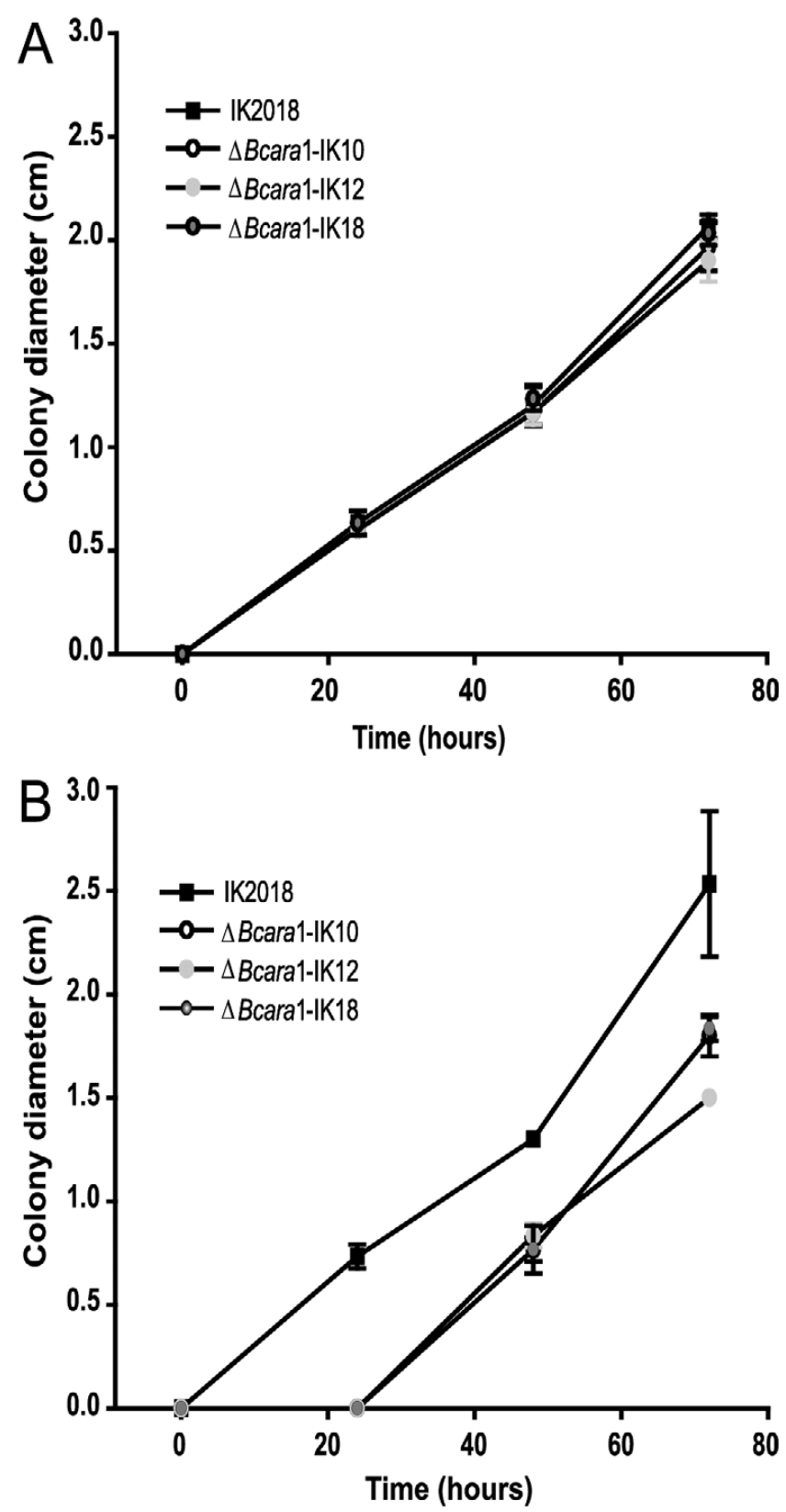

Fig. 7. Colony diameters of Botrytis cinerea wild type (IK2018) and three independent $\Delta$ Bcara 1 mutants on various media. B. cinerea IK2018 and mutants $\Delta B$ cara 1 -IK10, $\Delta$ Bcara 1 -IK12, and $\Delta B$ cara 1 -IK18 on agar plates containing A, potato dextrose or B, Gamborg's B5 minimal media with azurine-dyed and cross-linked arabinan as carbon source. Diameters of the colonies were measured over time (h). Values are means of three samples \pm standard deviation.
We considered the possibility that degradation products of arabinan by endo-arabinanases might act as an elicitor of defense activation in Arabidopsis. Release of hydrogen peroxide, known as the oxidative burst, is one of the canonical responses of plants to elicitors (Lamb and Dixon 1997). However, neither arabinobiose, linear arabinan treated with a commercial endo-arabinanase, nor purified branched arabinooligosaccharides obtained from sugar beets induced an oxidative burst in Arabidopsis seedlings (Supplementary Fig. S4) whereas the positive control (oligogalacturonides) did.

\section{Bcaral is not required for full virulence}

of $B$. cinerea on $N$. benthamiana and tomato.

$\Delta B$ cara 1 mutants were also tested for virulence on detached tomato leaves and on leaves of intact $N$. benthamiana plants. None of the mutants in the genetic background of either $\mathrm{B}$. $\mathrm{Ci}$ nerea IK2018 or strain B05.10 displayed reduced lesion sizes compared with the respective wild types (Supplementary Fig. S5).

Expression of arabinan-degrading activities were assessed in leaf tissues of $N$. benthamiana and Arabidopsis infected with B. cinerea IK 2018 at $62 \mathrm{hpi}$; at which time point the lesion sizes were similar in both species ( 0.6 to $0.8 \mathrm{~cm}$ in diameter). Leaf discs with a diameter of approximately $1 \mathrm{~cm}$ containing the lesions were excised and proteins were extracted in water and spotted on solidified citric-acid medium with AZCL-arabinan. Blue halos, indicative of endo-arabinanase activity, developed around the wells with extracts from infected Arabidopsis plants (Fig. 9A) whereas little color development was seen around the wells with extracts from infected $N$. benthamiana (Fig. 9A). Transcript levels of the Bcaral gene in Arabidopsis and $N$. benthamiana leaf tissues infected with $B$. cinerea at the same time point were determined by quantitative real-time PCR. The expression of Bcara1 is approximately three times lower in infected $N$. benthamiana tissues compared with infected Arabidopsis tissues (Fig. 9B). These results show that the transcript level of Bcaral and the expression of arabinandegrading activities differ depending on the hosts and that Bcaral plays a host-dependent role in the virulence of $\mathrm{B}$. $\mathrm{Ci}$ nerea.

\section{DISCUSSION}

In plants, pectic arabinans play roles in flexibility and mechanical stress tolerance of the plant cell wall. Most phytopathogenic fungi secrete arabinan-degrading enzymes, which are assumed to be important for plant cell-wall degradation; however, their roles in virulence have been elusive thus far. In this study we identified the endo-arabinanase BcAral from $B$. cinerea, characterized its enzymatic activity, and showed that BcAra1 is necessary for full virulence of B. cinerea on Arabidopsis. Our study is the first example of an endo-arabinanase as a virulence factor in phytopathogenic fungi.

BcAra1 is an endo-arabinanase in B. cinerea.

We provided several lines of evidence that, together, demonstrate that Bcara1 (locus tag BC1G_10322) encodes an endoarabinanase. First, bioinformatic analysis identified one gene in the $B$. cinerea B05.10 genome that has significant homology to a functionally characterized endo-arabinanase from $A$. aculeatus CBS 101 belonging to the CAZy family GH43 (Skjot et al. 2001). Second, heterologously expressed BcAra1 hydrolyzed linear and debranched arabinans but not arabinobiose, branched arabinan, or other major arabinose-containing polymers tested (Table 3). Third, the hydrolysis products of linear arabinan by BcAral were abundant in arabinooligosaccharides with DP of 3 or larger (Fig. 3). This pattern of products corresponds to 
those generated by previously characterized endo-arabinanases from A. niger (Flipphi et al. 1993), A. aculeatus (Pitson et al. 1997; Skjot et al. 2001), A. nidulans (Bauer et al. 2006), Penicillium chrysogenum (Sakamoto et al. 2003, 2012), Phanerochaete chrysosporium (Huy et al. 2013), and Chrysosporium lucknowense (Kuhnel et al. 2010). Finally, $\Delta$ Bcara 1 knockout mutants were impaired in the production of endo-arabinanase activity in the culture medium (Fig. 6) as well as deficient in growth on arabinan as the sole carbon source (Fig. 7). It is noteworthy that the fungal endo-arabinanases characterized
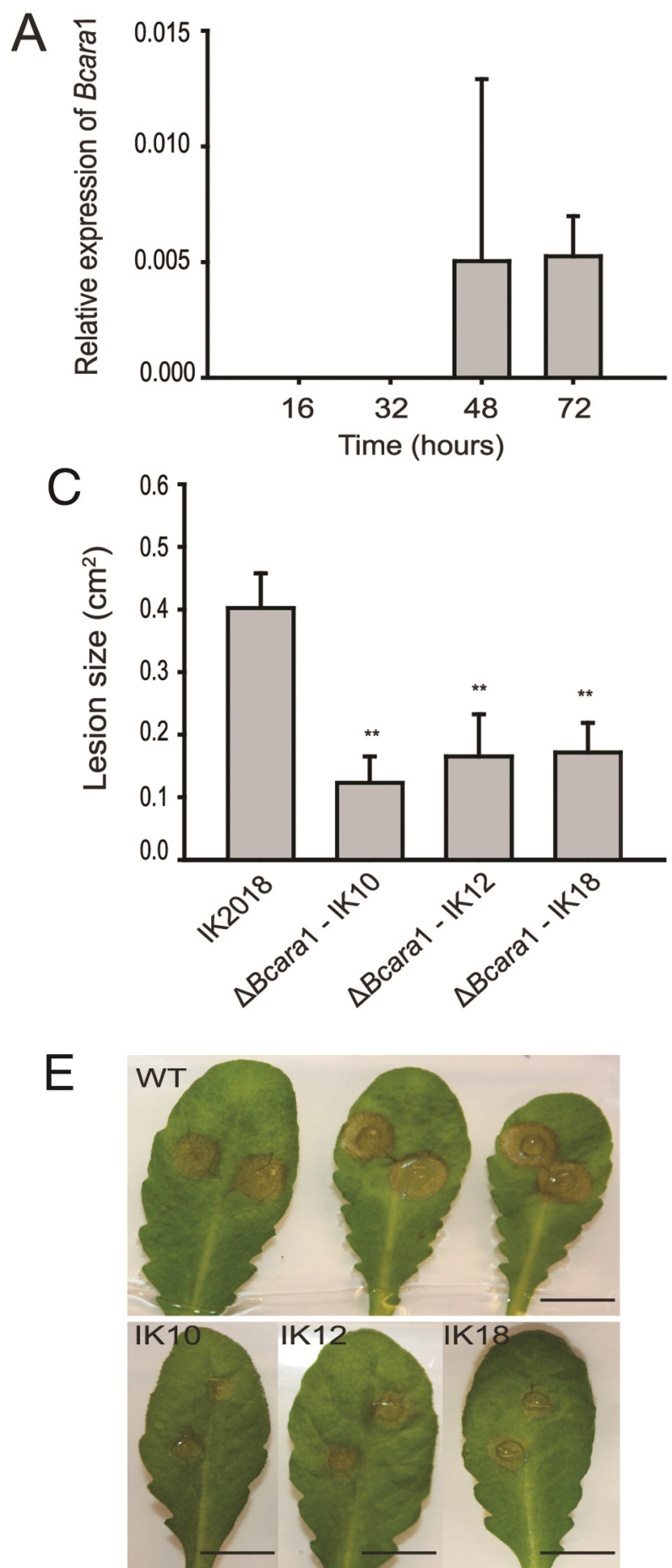
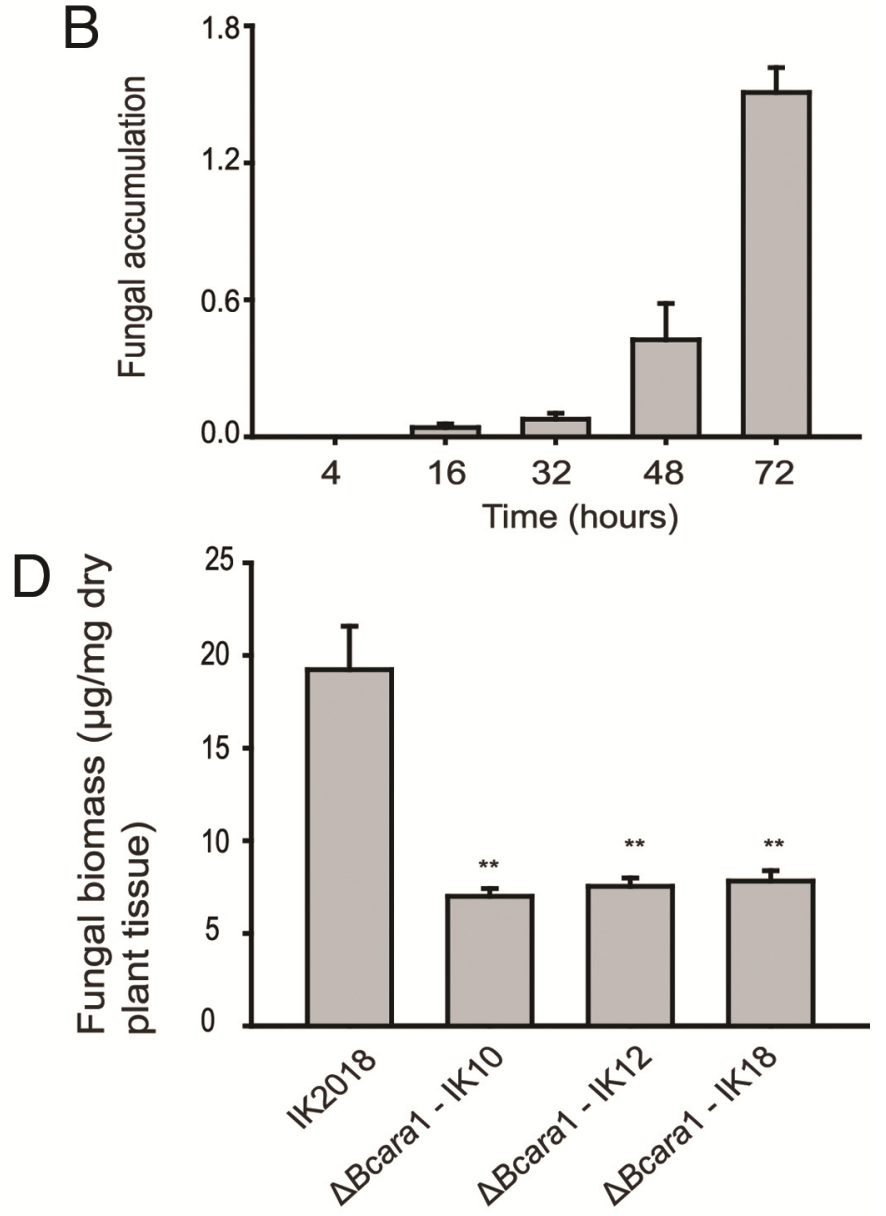

Fig. 8. Role of Bcara 1 in infection of Arabidopsis ecotype Columbia 0. A, Quantitative reverse-transcriptase polymerase chain reaction (RT-PCR) analysis of the Bcara1 transcript during infection of Arabidopsis leaves. Bcaral transcript levels are indicated relative to levels of BcActA (Benito et al. 1996). The values are means of three biological replicates \pm standard deviation (SD). B, Quantitative RT-PCR analysis of Botrytis cinerea biomass during infection of Arabidopsis leaves. BcActA transcript levels are indicated relative to Arabidopsis actin (AtACTIN). Values are means of three biological replicates \pm SD. C, Expanding lesion sizes on leaves of Arabidopsis ecotype Columbia 0 upon infection by B. cinerea wild type (WT) (IK2018) and three independent $\Delta B c a r a 1$ mutants. Measurements were made at 3 days postinfection (dpi). Values are means \pm standard error $(n \geq 16)$. Asterisks indicate data sets statistically different from the WT, according to Student's $t$ test $(P<0.01)$. The experiment was repeated three times with similar results. D, Immunological detection of $B$. cinerea biomass during infection of Arabidopsis leaves. Data represent average $\pm \mathrm{SD}(n=4)$. Asterisks indicate data sets statistically different from the WT, according to Student's $t$ test $(P<0.01)$. Arabidopsis leaves were inoculated with two drops $\left(5 \mu 1\right.$ of $^{1} 10^{6}$ spores ml $\left.{ }^{-1}\right)$ of conidial suspension. Measurements were made at 3 dpi. E, Representative images of Arabidopsis leaves infected with B. cinerea WT and $\Delta$ Bcara 1 mutants. Scale bars $=1 \mathrm{~cm}$. 
thus far are all secreted, whereas a bacterial endo-arabinanase from Bacillus thermodenitrificans was reported to be intracellular (Takao et al. 2002). BcAra1 contains a predicted N-terminal signal peptide and was found in the culture supernatant after centrifugation and desalting. A previous study detected BcAral in the secretome $16 \mathrm{~h}$ after transfer to plant media (Espino et al. 2010). Therefore, we concluded that BcAra1 is a secreted endo-arabinanase.

As noted above, bioinformatics analysis performed in this and other studies identified Bcara1 as the only gene coding for an endo-arabinanase in the Botrytis cinerea genome (Table 1) (Amselem et al. 2011; Benoit et al. 2012). The observation that culture supernatant of $\Delta B$ cara 1 failed to generate longer arabinooligosaccharides than arabinobiose when incubated with linear arabinan (Fig. 6) suggests that BcAra1 is the major endoarabinanase expressed under the conditions tested. The growth of the $\Delta B$ cara 1 mutants in the medium containing linear arabinan as the sole carbon source was impaired up to $24 \mathrm{hpi}$ (Fig. 7B). However, in subsequent days, growth of the $\Delta$ Bcaral
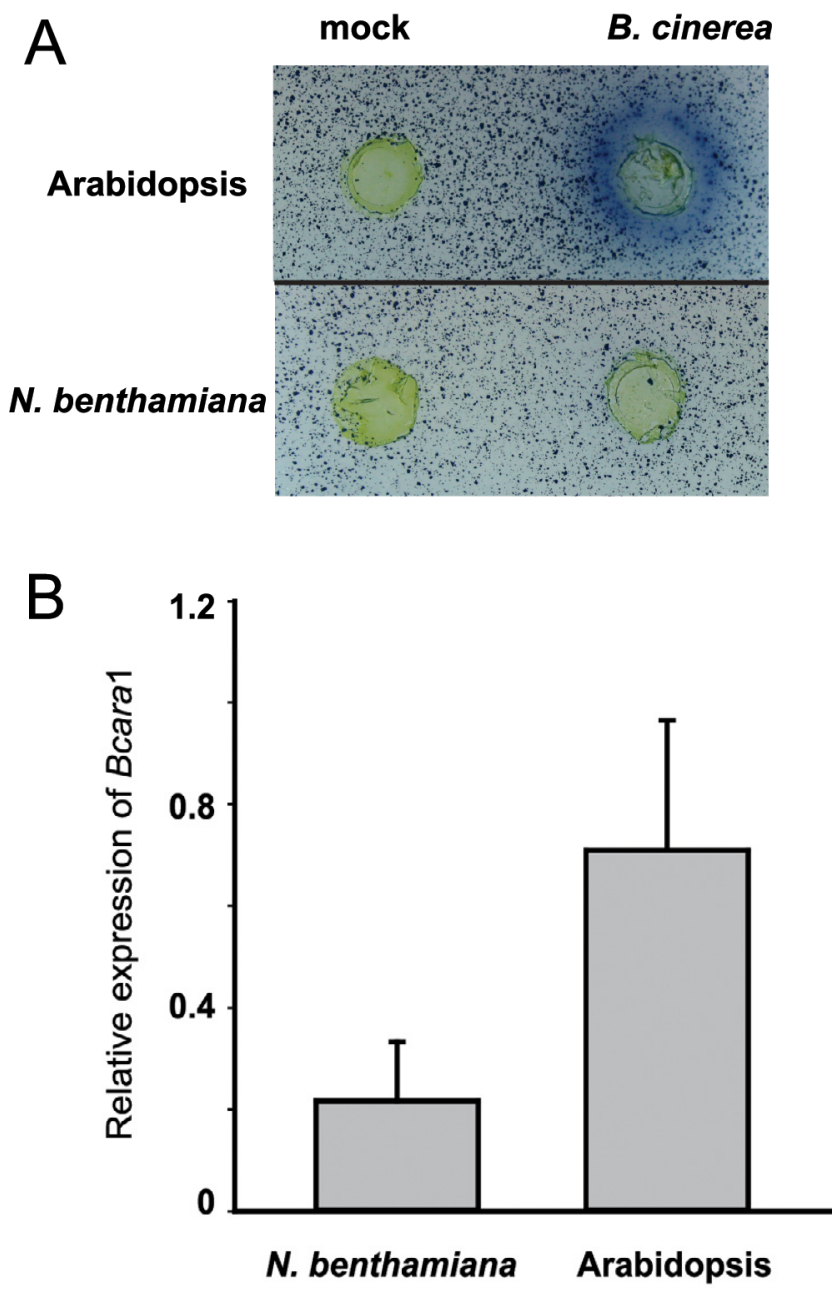

Fig. 9. Differential arabinanase activity during infection of plants. A, Arabinan-degrading activity in crude protein extract from infected Arabidopsis (top panel) and Nicotiana benthamiana (lower panel) plants visualized by agar plate diffusion assay with azurine-dyed and crosslinked arabinan. Detached leaves were infected with buffer (mock) or Botrytis cinerea spore solution for $66 \mathrm{~h}$. Crude protein extract $(100 \mu \mathrm{l})$ was spotted in each well and the plates were incubated for $72 \mathrm{~h}$. B, Quantitative reverse-transcriptase polymerase chain reaction analysis of the Bcaral transcript in infected Arabidopsis and tobacco leaves. Bcara 1 transcript levels are indicated relative to levels of BcActA (Benito et al. 1996). Values are means of three biological replicates \pm standard deviation. mutants resumed at a rate similar to that of IK2018 (Fig. 7B). This suggests that other arabinan-degrading activities, likely arabinofuranosidases, are expressed. The delayed growth is due to the slower breakdown of arabinan by arabinofuranosidases because complete degradation of arabinan often requires the concerted action of endo-arabinanases and arabinofuranosidases (Seiboth and Metz 2011). Expression of both activities appeared to be suppressed when $B$. cinerea was grown in potato dextrose broth (PDB) that contains high amounts of readily metabolized glucose. Therefore, similarly to almost all endo-arabinanases characterized so far (Seiboth and Metz 2011), it is likely that both BcAral and the other arabinandegrading activities are under catabolite repression.

\section{Role of BcAra1 during infection of Arabidopsis.}

To date, roles of endo-arabinanases during pathogenesis have been elusive. In this study, we showed that Bcara 1 is necessary for full virulence of $B$. cinerea during infection of Arabidopsis. Bcara 1 was shown to be expressed during infection of Arabidopsis (Fig. 8A), and the knockout mutants generated in both strains IK2018 and B05.10 exhibited considerably reduced lesion sizes on Arabidopsis leaves compared with the wild types (Fig. 8C; data not shown). It is noteworthy that the Bcaral transcript was not detectable by 32 hpi (Fig. 8A) and the frequency of initial infection was not affected in the $\Delta B$ cara 1 mutants. Therefore, Bcara 1 is not involved in penetration and primary colonization; rather, it plays a major role during the expansion of the colonies across neighboring host cells. In Fusarium graminearum, the expression of 16 arabinanases (from CAZy families GH43, GH51, GH54, and GH62) during growth in wheat coleoptiles was also reported to dramatically increase during the "destructive trespassing of neighboring cells" (Zhang et al. 2012). It is noteworthy that $B$. cinerea IK 2018 and the $\Delta$ Bcara 1 -IK10 mutant grew in vitro on cell wall polysaccharides isolated from Arabidopsis leaves similarly to the sole carbon source. This may suggest that the reduced virulence of the $\Delta B$ cara 1 -IK10 mutant in Arabidopsis is not due to reduced accessibility to cell-wall-derived arabinose as a carbon source. It is more likely that, in Arabidopsis, arabinan serves as a physical barrier and endo-arabinanase is required to efficiently depolymerize it in order for the pathogen to spread across neighboring cells.

\section{Host-dependent expression and function of BcAra1.}

Previous studies have shown that the composition of $\mathrm{B}$. $\mathrm{ci}$ nerea-secreted proteins differs depending on the plant extracts in which the fungus was cultivated. It has been reported that the endo-PG BcPG1 was found in the culture media of $\mathrm{B}$. $\mathrm{ci}$ nerea $\mathrm{B} 05.10$ grown on glucose, tomato, and kiwi fruit extract but not on strawberry extract (Espino et al. 2010). Likewise, BcAra1 was identified in the early secretome of $B$. cinerea when grown in the presence of kiwi fruit extract but not in the presence of tomato (Espino et al. 2010), suggesting the hostdependent induction of BcAra1. Our results showed that arabinan-degrading activity was barely detectable in the $N$. benthamiana tissues infected with $B$. cinerea whereas it was highly abundant in the Arabidopsis tissues infected with $\mathrm{B}$. $\mathrm{Ci}$ nerea. Furthermore, the level of the Bcaral transcript was considerably lower in the infected $N$. benthamiana compared with the infected Arabidopsis. Consistently, $\Delta$ Bcara 1 mutants showed reduced virulence in Arabidopsis but not in N. benthamiana. These results indicate that the BcAral expression is regulated at the transcriptional level by hosts and serves as a determinant of disease progression.

Host-dependent expression has also been observed for other genes related to cell-wall degradation in $B$. cinerea. The expression of endo-PG genes during infection was shown to depend 
on plant hosts, although no strict correlation with the expression pattern and corresponding knock-out mutant phenotypes was observed, which is likely due to redundancies (ten Have et al. 2001). Host-specific virulence has been observed for $B$. $\mathrm{ci}$ nerea mutants deficient in protein $O$-mannosyltransferase 1 (Gonzalez et al. 2013) and mutants deficient in D-galacturonic acid catabolism (Zhang and van Kan 2013a). In the latter case, the mutants have reduced virulence on $N$. benthamiana and Arabidopsis leaves but not on tomato, and this difference was correlated with the amount of D-galacturonic acid in the isolated cell wall materials from these hosts (Zhang and van Kan 2013a). The arabinose content in $N$. benthamiana has been reported to be approximately $30 \%$ lower than that in Arabidopsis (Zhang and van Kan 2013a), although it is not known which specific arabinose-containing polymers (e.g., arabinan, arabinogalactan proteins, or extensions) contribute to the difference. It is possible that the different levels of the Bcara 1 transcript and the different role of BcAral during the infection of Arabidopsis and $N$. benthamiana is attributable to the quantitative difference of arabinose in the cell walls. It is also possible that the qualitative difference (namely, difference in the precise structural organization) contributes to the observed difference. In Arabidopsis, branched arabinan is present throughout stem tissues whereas linear and long stretches of 1,5-linked arabinosyl residues detectable by the LM13 antibody are specifically found at the epidermal cell wall (Harholt et al. 2006; Verhertbruggen et al. 2009, 2013). In contrast, in tobacco, the LM13-detectable 1,5-linked arabinosyl residues are distributed throughout the stem tissue (Verhertbruggen et al. 2009). Given that linear arabinan interacts with homogalacturonan in muro in tobacco stems (Marcus et al. 2008) and binds cellulose in higher absorption affinity than branched arabinan in vitro (Zykwinska et al. 2005), the different arabinan structure and distribution in these host plants may differentially affect the ultrastructure of cell wall polymers and its susceptibility to the fungal hydrolytic enzymes. This could, in turn, lead to compositional differences in sugars released by these hydrolytic enzymes and to differential expression of cell-wall-degrading enzymes in these plant hosts. Given the large host range of $B$. cinerea, we expect that the expression of Bcaral varies during infection of different plant hosts and that lack of endo-arabinanase activity may negatively impact virulence on some hosts but not the others. Because of the complex nature of plant cell walls and genetic redundancy of fungal cell-wall-degradation enzymes, the molecular basis of interaction between the host cell walls and fungal hydrolytic enzymes is superficially understood to date. Our findings present a relatively simple model system wherein genetic regulation of a cell-wall-degrading enzyme of a pathogen and identities and roles of host factors can be studied in order to gain better understanding of molecular events that unfold at the host cell surface.

\section{MATERIALS AND METHODS}

\section{Growth of fungal strains and Arabidopsis plants.}

B. cinerea strains IK2018 (Manabe et al. 2011) and B05.10 were maintained on PDA (Scharlau, Barcelona, Spain). Conidia were harvested in PDB (Difco International, Leeuwarden, The Netherlands) and filtered through Miracloth (Merck, Hellerup, Denmark). Conidial suspensions were incubated for $4 \mathrm{~h}$ in PDB to allow for germination, and then used directly or centrifuged at $5,000 \times g$ to pellet the fungi and to replace the medium with water or a buffer, as indicated below.

Seed of Arabidopsis thaliana L. Heyn., Colombia wild-type for hydrogen peroxide measurements were surface sterilized and grown in 12-well plates containing Murashige and Skoog medium (Sigma-Aldrich, Brøndby, Denmark) at $1 \mathrm{ml}$ per well, adjusted to $\mathrm{pH} 5.7$, and supplemented with $0.5 \%$ (wt/vol) sucrose. Plates were incubated at $22^{\circ} \mathrm{C}$ with a photoperiod of $16 \mathrm{~h}$ of light and $8 \mathrm{~h}$ of darkness. After 7 days, the medium was replaced and the treatments performed the following day. Light intensity for soil-grown and liquid-grown plants was $120 \mu \mathrm{mol}$ photons $\mathrm{m}^{-2} \mathrm{~s}^{-1}$.

\section{Analysis of arabinanase activity.}

To detect arabinan-degrading activity, a plate assay with AZCL-arabinan was used. Plates consisted of a bottom layer made of a citrate buffer (100 mM sodium citrate buffer, $\mathrm{pH}$ 5.4 , and $1.5 \%$ [wt/vol] agarose), PDA, or soy peptone agar $(0.5 \%$ [wt/vol] soy peptone [Difco International] and $1.5 \%$ [wt/vol] agar) and a top layer of $0.1 \%$ (wt/vol) AZCL-arabinan, $100 \mathrm{mM}$ sodium citrate buffer $(\mathrm{pH} \mathrm{5.4)}$, and $0.5 \%$ (wt/vol) agarose. Wells with a diameter of $5 \mathrm{~mm}$ were punched in the top agar, into which the fungal spores in water or the crude extracts were added. Substrate degradation was detected by color development (halo). The plates were incubated at $28^{\circ} \mathrm{C}$ for 1 to 4 days. AZCL-arabinan was purchased from Megazyme (Wicklow, Ireland).

\section{Heterologous expression in $N$. benthamiana.}

The coding sequence of Bcara1 was amplified from total RNA extracted from $B$. cinerea-infected Arabidopsis leaves. The Bcara 1 coding sequence was cloned in the MP27 vector by USER cloning, as previously described (Nour-Eldin et al. 2006; Sakuragi et al. 2011). The primers used to amplify the gene (Supplementary Table S1) were the following: the forward primer Nt557 and the reverse primers Nt560 for construction of the plasmid bearing Bcaral and Nt571 for construction of the plasmid bearing Bcaral fused to a nucleic acid sequence encoding HDEL. Agrobacterium tumefaciens (C58 pGV3850) was transformed with the above-mentioned plasmid constructs and subsequently used to transiently transform $N$. benthamiana together with the p19 gene, as previously described (Sakuragi et al. 2011; Voinnet et al. 2003). The transformed plants were allowed to grow in the greenhouse for 3 or 4 days before extraction of proteins.

\section{Protein extraction.}

$N$. benthamiana leaves were homogenized in ice-cold buffer (100 mM sodium citric acid buffer, pH 5.5) containing complete proteinase inhibitor (Roche, Hvidovre, Denmark). The homogenate was centrifuged at $10,000 \times g$ for $15 \mathrm{~min}, 4^{\circ} \mathrm{C}$, and the supernatants were transferred to new tubes. For desalting, the supernatants were passed through Amicon Ultra columns (Millipore, Hellerup, Denmark) with a molecular cut-off of $10 \mathrm{kDa}$. Protein concentrations were determined by the Bradford method (Bio-Rad Laboratories, Copenhagen).

\section{Enzyme activity assay.}

Enzymatic activity was determined using linear arabinan from sugar beet (Megazyme) as a substrate. Substrate specificity was determined using linear and debranched arabinan from sugar beet (Megazyme), sugar beet arabinan (Megazyme), larch wood arabinogalactan (Megazyme), wheat arabinoxylan (Megazyme), birch xylan (Sigma-Aldrich), and 1,5- $\alpha$-arabinobiose (Megazyme). The $0.5 \%$ (wt/vol) substrate solution (500 $\mu \mathrm{l})$ in $100 \mathrm{M}$ sodium citrate buffer, $\mathrm{pH}$ 5.5, was incubated with crude $N$. benthamiana extract or $B$. cinerea culture supernatant for various times at $35^{\circ} \mathrm{C}$. The reactions were stopped by boiling for $20 \mathrm{~min}$. The release of reducing sugars was measured by the 3,5 dinitrosalicylic acid method (Miller 1959). One unit of enzyme activity corresponds to the release of L-arabinose at $1 \mu \mathrm{mol} / \mathrm{min}$. Endo-arabinanase and arabinofuranosidase preparations from Aspergillus niger were purchased from Megazyme. 
PACE of arabinooligosaccharides,

The hydrolysis products obtained after digestion of linear arabinan were analyzed using PACE. The samples were dried under vacuum and derivatized with 8-aminoaphtalene-1,3,6trisulfonic acid disodium (Life Technologies Europe, Naerum, Denmark), as described by Goubet and associates (2002). The derivatized samples were resuspended in $100 \mu \mathrm{l}$ of $3 \mathrm{M}$ urea (standards were resuspended in $100 \mu \mathrm{l}$ of $6 \mathrm{M}$ urea) and stored at $-20^{\circ} \mathrm{C}$. Samples $(5 \mu \mathrm{l}$ each) were separated using the Hoefer SE660 vertical slab gel electrophoresis apparatus (Hoefer Inc., Holliston, MA, U.S.A.) ,as previously described (Kosik et al. 2012). The gels were visualized using a Genebox (Syngene, Herlev, Denmark) and images were acquired using Genesnap (Syngene) software. Arabinose (Sigma-Aldrich) and purified arabinooligosaccharides (arabinobiose, arabinotetraose, arabinopentaose, arabinohexaose, and arabinoheptaose) (Megazyme) were used as standards.

\section{Generation of $B$. cinerea arabinanase knockout mutants.}

The gene replacement strategy for generating $B$. cinerea knockout constructs, $B$. cinerea protoplast transformation, and PCR-based screening of transformants were previously described (Kars et al. 2005b). The hygromycin resistance cassette containing $h p h$, derived from vector pLOB7 (Zhang et al. 2011) with primers 20/21, was used as the selection marker to replace the target gene. Genomic DNA of transformants was screened by PCR with primers KOC-F and KOC-R. The complementation fragments of Bcara1, including approximately 1,500-bp upstream and approximately 200-bp downstream sequences of the coding region, were amplified using IK2018 genomic DNA as template with primers Comp-F and Comp-R which contain attB1 and attB2 sites, respectively. The purified fragments were recombined with pNR4 (Zhang et al. 2011) in $\mathrm{BP}$ reactions (Life Technologies Europe) in the appropriate concentration. The resulting plasmids were used for transformation of the $\Delta$ Bcara $1-\mathrm{IK} 10$ mutant.

\section{Growth of IK2018 and replacement mutants on various growth media.}

B. cinerea conidial suspension $\left(2 \mu \mathrm{l}\right.$ at $5 \times 10^{5}$ conidia $\left.\mathrm{ml}^{-1}\right)$ were spotted in the middle of agar plates with potato dextrose, soy peptone, or Gamborg's B5 medium containing AZCLarabinan as the carbon source. The plates were incubated at $25^{\circ} \mathrm{C}$ and the diameters of the expanding colonies were measured over time.

\section{RNA extraction, cDNA synthesis, and quantitative reverse-transcriptase PCR analysis.}

Total RNA was extracted from frozen leaf tissue using the Spectrum plant total RNA kit (Sigma-Aldrich) according to the manufacturer's instructions, with on-column DNase treatment. Integrity of the RNA was analyzed by gel electrophoresis and the amount quantified by NanoDrop (Thermo Scientific, Wilmington, DE, U.S.A.). First-strand cDNA synthesis was performed using the iScript cDNA synthesis kit (Bio-Rad Laboratories). The Dynamo SYBR green mastermix (Thermo Scientific) in combination with Rotor-Gene PCR cycler (Qiagen, Copenhagen) were used for quantitative PCR amplifications.

\section{Plant infection.}

Infection of Arabidopsis leaves was done as by Manabe and associates (2011). Briefly, two drops of a 5- $\mu$ l B. cinerea conidia solution $\left(5 \times 10^{5}\right.$ conidia $\mathrm{ml}^{-1}$ in PDB) were applied to detached leaves from 4-week-old plants, with their petioles in $0.6 \%$ (wt/vol) water agar. The plates were sealed with Saran wrap and incubated at $24^{\circ} \mathrm{C}$. For quantification of lesion sizes, high-resolution photographs were analyzed in ImageJ. Leaves of 5- to 6-week-old Solanum lycopersicum (tomato) and $N$. benthamiana plants were inoculated with $B$. cinerea (Zhang and van Kan 2013a). Each mutant was tested in two independent experiments.

\section{Growth analysis of $B$. cinerea on Arabidopsis cell wall materials or polygalacturonic acid as the carbon source.}

Cell wall preparations (alcohol-insoluble residue) were isolated from Arabidopsis leaves as previously described (Fry 1988). Briefly, lyophilized leaves were finely ground with metal balls in a Mixer Mill (Retsch, Slangerup, Denmark) and washed with $70 \%$ (vol/vol) ethanol until free of chlorophyll. The pellet was washed with $100 \%$ (vol/vol) acetone and dried under vacuum. The alcohol-insoluble residues or polygalacturonic acid (Sigma-Aldrich) at a concentration of $10 \mathrm{mg} \mathrm{ml}^{-1}$ were added to Gamborg's B5 medium (Difco) and solidified with $1.2 \%$ (vol/wt) agarose. Agar plugs with a diameter of 5 $\mathrm{mm}$ were removed from the growing edge of a dark-grown $B$. cinerea colony and placed on the plates, which were incubated at $25^{\circ} \mathrm{C}$. The growth was assessed every day for 4 days.

\section{Determination of $\mathrm{H}_{2} \mathrm{O}_{2}$.}

The concentration of $\mathrm{H}_{2} \mathrm{O}_{2}$ in the incubation medium of seedlings was measured by the Amplex Red hydrogen peroxide/peroxidase kit (Life Technologies Europe) following the manufacturer's instruction. To determine $\mathrm{H}_{2} \mathrm{O}_{2}$ concentration, $50 \mu \mathrm{l}$ of the incubation medium was added to $50 \mu \mathrm{l}$ of the assay reagent and incubated for $45 \mathrm{~min}$. Fluorescence was measured with a SpectraMax M5 plate reader (Molecular Devices, Oslo, Norway) using excitation at $530 \mathrm{~nm}$ and detection at $590 \mathrm{~nm}$. The concentration of $\mathrm{H}_{2} \mathrm{O}_{2}$ in each sample was calculated using a standard curve and expressed as micromoles per milligram of fresh weight of seedlings.

\section{ACKNOWLEDGMENTS}

We thank H. Schols (Wageningen University, Food Chemistry) for kindly providing the branched arabinan fragments from sugar beet.The research leading to these results has received funding from Danish Advanced Technology Foundation (001-2011-4), Nordic Research Energy (AquaFEED), European Union's Seventh Framework Programme FP7-ENERGY-2010-1 under REA grant agreement number 256808 (DirectFuel), the People Programme (Marie Curie Actions) FP7/2007-2013 under REA grant agreement number 317184 (PHOTO.COMM). M. Nafisi received funding from EU FP7 the People Programme (Marie Curie Actions) under REA grant agreement number 275597 (Endophyte). L. Zhang received funding from the Foundation Technological Top Institute Green Genetics (Project 2CC035RP) and from the Netherlands Graduate School of Experimental Plant Sciences.

\section{LITERATURES CITED}

Amselem, J., Cuomo, C. A., van Kan, J. A., Viaud, M., Benito, E. P. Couloux, A., Coutinho, P. M., de Vries, R. P., Dyer, P. S., Fillinger, S., Fournier, E., Gout, L., Hahn, M., Kohn, L., Lapalu, N., Plummer, K. M., Pradier, J. M., Quevillon, E., Sharon, A., Simon, A., ten Have, A., Tudzynski, B., Tudzynski, P., Wincker, P., Andrew, M., Anthouard, V., Beever, R. E., Beffa, R., Benoit, I., Bouzid, O., Brault, B., Chen, Z., Choquer, M., Collemare, J., Cotton, P., Danchin, E. G., Da Silva, C., Gautier, A., Giraud, C., Giraud, T., Gonzalez, C., Grossetete, S., Guldener, U., Henrissat, B., Howlett, B. J., Kodira, C., Kretschmer, M., Lappartient, A., Leroch, M., Levis, C., Mauceli, E., Neuveglise, C., Oeser, B., Pearson, M., Poulain, J., Poussereau, N., Quesneville, H., Rascle, C., Schumacher, J., Segurens, B., Sexton, A., Silva, E., Sirven, C., Soanes, D. M., Talbot, N. J., Templeton, M., Yandava, C., Yarden, O., Zeng, Q., Rollins, J. A., Lebrun, M. H., and Dickman, M. 2011. Genomic analysis of the necrotrophic fungal pathogens Sclerotinia sclerotiorum and Botrytis cinerea. PLoS Genet. 7:e1002230.

Bauer, S., Vasu, P., Persson, S., Mort, A. J., and Somerville, C. R. 2006. Development and application of a suite of polysaccharide-degrading 
enzymes for analyzing plant cell walls. Proc. Natl. Acad. Sci. U.S.A. 103:11417-11422.

Benito, E. P., Prins, T. W., and van Kan, J. A. 1996. Application of differential display RT-PCR to the analyses of gene expression in an plantfungus interaction. Plant Mol. Biol. 32:947-957.

Benoit, I., Coutinho, P. M., Schols, H. A., Gerlach, J. P., Henrissat, B., and de Vries, R. P. 2012. Degradation of different pectins by fungi: Correlations and contrasts between the pectinolytic enzyme sets identified in genomes and the growth on pectins of different origin. BMC Genomics 13:321-332.

Carpita, N. C., and Gibeaut, D. M. 1993. Structural models of primary cell walls in flowering plants: Consistency of molecular structure with the physical properties of the walls during growth. Plant J. 3:1-30.

Cooper, R. M., and Wood, R. K. S. 1975. Regulation of synthesis of cellwall degrading enzymes by Verticillium albo-atrum and Fusarium oxysporum f. sp. lycopersici. Physiol. Plant Pathol. 5:135-156.

Dean, R., Van Kan, J. A. L., Pretorius, Z. A., Hammond-Kosack, K. E., Di Pietro, A., Spanu, P. D., Rudd, J. J., Dickman, M., Kahmann, R., Ellis, J., and Foster, G. D. 2012. The Top 10 fungal pathogens in molecular plant pathology. Mol. Plant Pathol. 13:414-430.

Emr, S. D., Schekman, R., Flessel, M. C., and Thorner, J. 1983. An MF alpha 1-SUC2 (alpha-factor-invertase) gene fusion for study of protein localization and gene expression in yeast. Proc. Natl. Acad. Sci. U.S.A. 80:7080-7084.

Espino, J. J., Gutierrez-Sanchez, G., Brito, N., Shah, P., Orlando, R., and Gonzalez, C. 2010. The Botrytis cinerea early secretome. Proteomics 10:3020-3034.

Fernandez-Acero, F. J., Colby, T., Harzen, A., Carbu, M., Wieneke, U., Cantoral, J. M., and Schmidt, J. 2010. 2-DE proteomic approach to the Botrytis cinerea secretome induced with different carbon sources and plant-based elicitors. Proteomics 10:2270-2280.

Flipphi, M. J. A., Panneman, H., Vanderveen, P., Visser, J., and Degraaff, L. H. 1993. Molecular-cloning, expression and structure of the endo1,5-alpha-L-arabinase gene of Aspergillus niger. Appl. Microbiol. Biot. 40:318-326.

Fry, S. C. 1988. The Growing Plant Cell Wall: Chemical and Metabolic Analysis. Longman, Scientific and Technical, Essex, U.K.

Gomez, L. D., Steele-King, C. G., Jones, L., Foster, J. M., Vuttipongchaikij, S., and McQueen-Mason, S. J. 2009. Arabinan metabolism during seed development and germination in Arabidopsis. Mol. Plant 2:966-976.

Gonzalez, M., Brito, N., Frias, M., and Gonzalez, C. 2013. Botrytis cinerea protein O-mannosyltransferases play critical roles in morphogenesis, growth, and virulence. PLoS One 8:e65924.

Goubet, F., Jackson, P., Deery, M. J., and Dupree, P. 2002. Polysaccharide analysis using carbohydrate gel electrophoresis: A method to study plant cell wall polysaccharides and polysaccharide hydrolases. Anal. Biochem. 300:53-68

Ha, M. A., Vietor, R. J., Jardine, G. D., Apperley, D. C., and Jarvis, M. C. 2005. Conformation and mobility of the arabinan and galactan sidechains of pectin. Phytochemistry 66:1817-1824.

Harholt, J., Jensen, J. K., Sorensen, S. O., Orfila, C., Pauly, M., and Scheller, H. V. 2006. ARABINAN DEFICIENT 1 is a putative arabinosyltransferase involved in biosynthesis of pectic arabinan in Arabidopsis. Plant Physiol. 140:49-58.

Houterman, P. M., Speijer, D., Dekker, H. L., de Koster, C. G., Cornelissen, B. J. C., and Rep, M. 2007. The mixed xylem sap proteome of Fusarium oxysporum-infected tomato plants. Mol. Plant Pathol. 8:215-221.

Howell, H. E. 1975. Correlation of virulence with secretion in vitro of three wall-degrading enzymes in isolates of Sclerotinia fructigena obtained after mutagen treatment. J. Gen. Microbiol. 90:32-40.

Huy, N. D., Thiyagarajan, S., Choi, Y. E., Kim, D. H., and Park, S. M 2013. Cloning and characterization of a thermostable endo-arabinanase from Phanerochaete chrysosporium and its synergistic action with endo-xylanase. Bioproc. Biosyst. Eng. 36:677-685.

Jones, L., Milne, J. L., Ashford, D., and McQueen-Mason, S. J. 2003. Cell wall arabinan is essential for guard cell function. Proc. Natl. Acad. Sci. U.S.A. 100:11783-11788.

Kars, I. 2007. The role of pectin degradation in pathogenesis of Botrytis cinerea. Ph.D. thesis, Wageningen University, Wageningen, The Netherlands.

Kars, I., Krooshof, G. H., Wagemakers, L., Joosten, R., Benen, J. A., and van Kan, J. A. 2005a. Necrotizing activity of five Botrytis cinerea endopolygalacturonases produced in Pichia pastoris. Plant J. 43:213-225.

Kars, I., McCalman, M., Wagemakers, L., and van Kan, J. A. 2005b. Functional analysis of Botrytis cinerea pectin methylesterase genes by PCRbased targeted mutagenesis: Bcpme1 and Bcpme 2 are dispensable for virulence of strain B05.10. Mol. Plant Pathol. 6:641-652.

Kosik, O., Bromley, J. R., Busse-Wicher, M., Zhang, Z. N., and Dupree, P. 2012. Studies of enzymatic cleavage of cellulose using polysaccha- ride analysis by carbohydrate gel electrophoresis (PACE). Methods Enzymol. 510:51-67.

Kuhnel, S., Hinz, S. W. A., Pouvreau, L., Wery, J., Schols, H. A., and Gruppen, H. 2010. Chrysosporium lucknowense arabinohydrolases effectively degrade sugar beet arabinan. Bioresource Technol. 101:8300-8307.

Lamb, C., and Dixon, R. A. 1997. The oxidative burst in plant disease resistance Annu. Rev. Plant Physiol. Plant Mol. Biol. 48:251-275.

Levigne, S. V., Ralet, M. C. J., Quemener, B. C., Pollet, B. N. L., Lapierre, C., and Thibault, J. F. J. 2004. Isolation from sugar beet cell walls of arabinan oligosaccharides esterified by two ferulic acid monomers. Plant Physiol. 134:1173-1180.

Manabe, Y., Nafisi, M., Verhertbruggen, Y., Orfila, C., Gille, S., Rautengarten, C., Cherk, C., Marcus, S. E., Somerville, S., Pauly, M., Knox, J. P., Sakuragi, Y., and Scheller, H. V. 2011. Loss-of-function mutation of REDUCED WALL ACETYLATION2 in Arabidopsis leads to reduced cell wall acetylation and increased resistance to Botrytis cinerea. Plant Physiol. 155:1068-1078.

Marcus, S. E., Verhertbruggen, Y., Herve, C., Ordaz-Ortiz, J. J., Farkas, V., Pedersen, H. L., Willats, W. G. T., and Knox, J. P. 2008. Pectic homogalacturonan masks abundant sets of xyloglucan epitopes in plant cell walls. BMC Plant Biol. 8:60-72.

McCleary, B. V. 1988. Soluble, dye-labelled polysaccharides for the assays of endo-hydrolases. Methods Enzymol. 160:74-86.

Miller, G. L. 1959. Use of dinitrosalicylic acid reagent for determination of reducing sugar. Anal. Chem. 31:426-428.

Mohnen, D. 2008. Pectin structure and biosynthesis. Curr. Opin. Plant Biol. 11:266-277.

Moore, J. P., Nguema-Ona, E., Chevalier, L., Lindsey, G. G., Brandt, W. F., Lerouge, P., Farrant, J. M., and Driouich, A. 2006. Response of the leaf cell wall to desiccation in the resurrection plant Myrothamnus flabellifolius. Plant Physiol. 141:651-662.

Moore, J. P., Farrant, J. M., and Driouich, A. 2008. A role for pectin-associated arabinans in maintaining the flexibility of the plant cell wall during water deficit stress. Plant Signal. Behav. 3:102-104.

Mullen, J. M., and Bateman, D. F. 1975. Polysaccharide degrading enzymes produced by Fusarium roseum "Avenaceum" in culture and during pathogenesis. Physiol. Plant Pathol. 6:233-246.

Nour-Eldin, H. H., Hansen, B. G., Norholm, M. H. H., Jensen, J. K., and Halkier, B. A. 2006. Advancing uracil-excision based cloning towards an ideal technique for cloning PCR fragments. Nucleic Acids Res. 34:e122.

Nurizzo, D., Turkenburg, J. P., Charnock, S. J., Roberts, S. M., Dodson, E. J., McKie, V. A., Taylor, E. J., Gilbert, H. J., and Davies, G. J. 2002. Cellvibrio japonicus alpha-L-arabinanase 43A has a novel five-blade beta-propeller fold. Nat. Struct. Biol. 9:665-668.

Petersen, T. N., Brunak, S., von Heijne, G., and Nielsen, H. 2011. SignalP 4.0: Discriminating signal peptides from transmembrane regions. Nat. Methods 8:785-786.

Pitson, S. M., Voragen, A. G. J., Vincken, J. P., and Beldman, G. 1997. Action patterns and mapping of the substrate-binding regions of endo-(1$>5$ )-alpha-L-arabinanases from Aspergillus niger and Aspergillus aculeatus. Carbohydr. Res. 303:207-218.

Ralet, M. C., Andre-Leroux, G., Quemener, B., and Thibault, J. F. 2005 Sugar beet (Beta vulgaris) pectins are covalently cross-linked through diferulic bridges in the cell wall. Phytochemistry 66:2800-2814

Ransom, R. F., and Walton, J. D. 1997. Purification and characterization of extracellular beta-xylosidase and alpha-arabinosidase from the plant pathogenic fungus Cochliobolus carbonum. Carbohydr. Res. 297:357364.

Rehnstrom, A. L., Free, S. J., and Pratt, R. G. 1994. Isolation, characterization and pathogenicity of Sclerotinia trifoliorum arabinofuranosidasedeficient mutants. Physiol. Mol. Plant Pathol. 44:199-206.

Ridley, B. L., O’Neill, M. A., and Mohnen, D. 2001. Pectins: Structure, biosynthesis, and oligogalacturonide-related signaling. Phytochemistry 57:929-967.

Sakamoto, T., Ihara, H., Kozaki, S., and Kawasaki, H. 2003. A coldadapted endo-arabinanase from Penicillium chrysogenum. Biochim. Biophys. Acta Gen. Subj. 1624:70-75.

Sakamoto, T., Inui, M., Yasui, K., Tokuda, S., Akiyoshi, M., Kobori, Y., Nakaniwa, T., and Tada, T. 2012. Biochemical characterization and gene expression of two endo-arabinanases from Penicillium chrysogenum 31B. Appl. Microbiol. Biot. 93:1087-1096.

Sakuragi, Y., Norholm, M. H., and Scheller, H. V. 2011. Visual mapping of cell wall biosynthesis. Methods Mol. Biol. 715:153-167.

Seiboth, B., and Metz, B. 2011. Fungal arabinan and L-arabinose metabolism. Appl. Microbiol. Biot. 89:1665-1673.

Shah, P., Atwood, J. A., Orlando, R., El Mubarek, H., Podila, G. K., and Davis, M. R. 2009a. Comparative proteomic analysis of Botrytis cinerea secretome. J. Proteome Res. 8:1123-1130. 
Shah, P., Gutierrez-Sanchez, G., Orlando, R., and Bergmann, C. 2009b. A proteomic study of pectin-degrading enzymes secreted by Botrytis cinerea grown in liquid culture. Proteomics 9:3126-3135.

Skjot, M., Kauppinen, S., Kofod, L. V., Fuglsang, C., Pauly, M., Dalboge, H., and Andersen, L. N. 2001. Functional cloning of an endo-arabinanase from Aspergillus aculeatus and its heterologous expression in $A$. oryzae and tobacco. Mol. Genet. Genomics 265:913-921.

Takao, M., Akiyama, K., and Sakai, T. 2002. Purification and characterization of thermostable endo-1,5-alpha-L-arabinase from a strain of Bacillus thermodenitrificans. Appl. Environ. Microbiol. 68:1639-1646.

ten Have, A., Mulder, W., Visser, J., and van Kan, J. A. 1998. The endopolygalacturonase gene Bcpg1 is required for full virulence of Botrytis cinerea. Mol. Plant-Microbe Interact. 11:1009-1016.

ten Have, A., Breuil, W. O., Wubben, J. P., Visser, J., and van Kan, J. A. L. 2001. Botrytis cinerea endopolygalacturonase genes are differentially expressed in various plant tissues. Fungal Genet. Biol. 33:97-105.

ten Have, A., Tenberge, K. B., Benen, J. A., Tudzynski, P., Visser, J., and Van Kan, J. 2002. The contributions of cell wall degrading enzymes to pathogenesis of fungal plant pathogens. Pages 341-358 in: The Mycota, vol. XI. F. Kempken, ed. Springer Verlag, Berlin.

Thompson, J. E., and Fry, S. C. 2000. Evidence for covalent linkage between xyloglucan and acidic pectins in suspension-cultured rose cells. Planta 211:275-286.

Urbanek, H., and Zalewskasobczak, J. 1984. Multiplicity of cell-wall degrading glycosidic hydrolases produced by apple infecting Botrytis cinerea. Phytopathol. Z. 110:261-271.

Valette-Collet, O., Cimerman, A., Reignault, P., Levis, C., and Boccara, M. 2003. Disruption of Botrytis cinerea pectin methylesterase gene Bcpme1 reduces virulence on several host plants. Mol. Plant-Microbe Interact. 16:360-367.

van Kan, J. A. 2006. Licensed to kill: The life style of a necrotrophic plant pathogen. Trends Plant Sci. 11:247-253.

Verhertbruggen, Y., Marcus, S. E., Haeger, A., Verhoef, R., Schols, H. A., McCleary, B. V., Mckee, L., Gilbert, H. J., and Knox, J. P. 2009. Developmental complexity of arabinan polysaccharides and their processing in plant cell walls. Plant J. 59:413-425.

Verhertbruggen, Y., Marcus, S. E., Chen, J. S., and Knox, J. P. 2013. Cell wall pectic arabinans influence the mechanical properties of Arabidopsis thaliana inflorescence stems and their response to mechanical stress. Plant Cell Physiol. 54:1278-1288.

Verhoeff, K., and Warren, J. M. 1972. Production of pectolytic enzymes by conidia of Botrytis cinerea. Acta Bot. Neerl. 21:110.

Vignon, M. R., Heux, L., Malainine, M. E., and Mahrouz, M. 2004. Arabinan-cellulose composite in Opuntia ficus-indica prickly pear spines. Carbohydr. Res. 339:123-131.

Voinnet, O., Rivas, S., Mestre, P., and Baulcombe, D. 2003. An enhanced transient expression system in plants based on suppression of gene silencing by the p19 protein of tomato bushy stunt virus. Plant J. 33:949956.

Williamson, B., Tudzynski, B., Tudzynski, P., and van Kan, J. A. 2007. Botrytis cinerea: The cause of grey mould disease. Mol. Plant Pathol. 8:561-580.

Zhang, L., and van Kan, J. A. L. 2013a. Botrytis cinerea mutants deficient in D-galacturonic acid catabolism have a perturbed virulence on Nicotiana benthamiana and Arabidopsis, but not on tomato. Mol. Plant Pathol. 14:19-29.

Zhang, L., and van Kan, J. A. L. 2013b. Pecin as a barrier and nutrient source for fungal plant pathogens. Pages 361-375 in: The Mycota, vol. XI. F. Kempken, ed. Springer, Berlin

Zhang, L., Thiewes, H., and van Kan, J. A. 2011. The D-galacturonic acid catabolic pathway in Botrytis cinerea. Fungal Genet. Biol. 48:990-997.

Zhang, X. W., Jia, L. J., Zhang, Y., Jiang, G., Li, X., Zhang, D., and Tang, W. H. 2012. In planta stage-specific fungal gene profiling elucidates the molecular strategies of Fusarium graminearum growing inside wheat coleoptiles. Plant Cell 24:5159-5176.

Zykwinska, A. W., Ralet, M. C. J., Garnier, C. D., and Thibault, J. F. J. 2005. Evidence for in vitro binding of pectin side chains to cellulose. Plant Physiol. 139:397-407.

\section{AUTHOR-RECOMMENDED INTERNET RESOURCES}

The Carbohydrate-Active enZYmes (CAZY) database: www.cazy.org ImageJ software: rsbweb.nih.gov/ij/docs/concepts.html 